\title{
Aprender sobre el medio ambiente: una propuesta de micros audiovisuales para la etapa preescolar
}

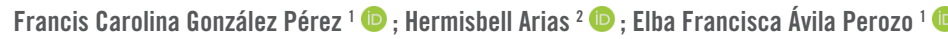 \\ ${ }^{1}$ Universidad Pedagógica Experimental Libertador (UPEL); ${ }^{2}$ Ministerio del Poder Popular para la Educación, República \\ Bolivariana de Venezuela
}

Resumen. La presente investigación tuvo como objetivo proponer micros audiovisuales para la mediación de los aprendizajes del componente curricular "Características, Cuidado y Preservación del Ambiente" en niños de edad preescolar (3-6 años) en un contexto vulnerable venezolano. El estudio cuantitativo, fue apoyado en una investigación de campo descriptivo. La población estuvo conformada por 38 docentes de Educación Inicial a quienes se les aplicó un cuestionario contentivo de 12 ítems. La metodología se produjo en tres fases: Diagnóstico, Diseño y Validación de la propuesta. Los resultados obtenidos en la fase I evidenciaron que un alto porcentaje de las docentes nunca usan los tipos de micros audiovisuales para la mediación de aprendizajes lo que determinó la necesidad de proponer su producción y recopilación. El diseño contiene una programación de 12 micros audiovisuales y fue validado por los usuarios. Se concluye que este material tecnológico es pertinente para la etapa preescolar, y la combinación mensaje-sonido-imagen, permite potenciar el desarrollo intelectual de los niños y concretar en breve tiempo los aprendizajes que se esperan lograr. Palabras clave: tecnología educativa; edad preescolar; medio ambiente.

Aprendendo sobre o meio ambiente: uma proposta de microvídeos para a Educação Infantil Resumo. A presente pesquisa teve como objetivo propor microvídeos para favorecer a aprendizagem de crianças de 3 a 6 anos de idade, do componente curricular "Características, Cuidados e Preservação do Meio Ambiente", em um contexto vulnerável da Venezuela. O estudo quantitativo foi apoiado por uma pesquisa de campo descritiva. A população, composta por 38 professores de Educação Infantil, respondeu a um questionário contendo 12 itens. A metodologia foi desenvolvida em três fases: diagnóstico, elaboração e validação da proposta. Os resultados obtidos na fase I demonstraram que uma alta porcentagem das professoras nunca usa microvídeos como material didático para facilitar a aprendizagem, o que levou à necessidade de propor sua produção e compilação. O projeto contém uma programação de 12 microvídeos e foi aprovado pelos usuários. $A$ conclusão é que este material tecnológico é relevante para a fase pré-escolar, e a combinação "mensagem-som-imagem" permite potencializar o desenvolvimento intelectual das crianças e conseguir em pouco tempo o aprendizado esperado.

Palavras-chave: tecnologia educacional; idade pré-escolar; meio ambiente.

Learning about the environment: a proposal with microsaudiovisuales for the preschool stage Abstract. This research aimed to propose audiovisual micros for the mediation of the learnings of the Characteristic Component, Care and Preservation of the Environment in preschool children (3-6 years) in a vulnerable Venezuelan context. The quantitative study was supported by descriptive field research. The population consisted of 38 teachers of Initial Education who were given a contentive questionnaire of 12 items. The methodology was produced in three phases: Diagnosis, Design and Validation of the proposal. The results obtained in phase / showed that a high percentage of teachers never use the types of audiovisual micros for learning mediation which determined the need to propose their production and compilation. The design contains a programming of 12 audiovisual microphones and was validated by users. It is concluded that this technological material is relevant to the preschool stage, and the message-sound-image combination, allows to enhance the intellectual development of children and soon concrete the learnings that are expected to be achieved

Keywords: educational technology; preschool age; environment. 


\section{Introducción}

La Educación Inicial, es el primer nivel del sistema educativo venezolano y pilar fundamental para la atención integral del niño de 0 a 6 años. De allí, que debe proveer experiencias de aprendizaje que les permitan construir conocimientos de acuerdo a su realidad social y natural para un desarrollo pleno y armónico (MED, 2005).

Hoy día, uno de los elementos que se integran al proceso formativo de los niños es el uso de las tecnologías las cuales están inmersas en la práctica docente para propiciar saberes, mediar y guiar experiencias que le brinden a los infantes un aprendizaje significativo y el desarrollo del pensamiento en un ambiente creativo, innovador y motivador. Vale destacar que en su sentido educativo, el uso de las tecnologías ha asumido diferentes acepciones que muchas veces son utilizadas para referirse a la misma categoría.

Por un lado, autores como Pinto, Díaz y Alfaro (2016) las denominan Tecnologías para el Aprendizaje y el Conocimiento (TAC) cuyo enfoque "requiere diseñar, implementar y evaluar actividades que van mucho más allá del uso instrumental de artefactos, sistemas y procesos, para apropiar un escenario que favorezca el interés y la gestión de aprender, ejercitar, ilustrar, proponer, interactuar y ejemplificar" (Pinto, Díaz y Alfaro, 2016, p.40). Otros autores, plantean la denominación tecnología educativa -la cual se asume en este estudio-, y es definida como "la disciplina pedagógica encargada de concebir, aplicar y valorar de forma sistemática los procesos de enseñanza y aprendizaje" (Torres y Cobo, 2017, p.32).

En este sentido, en el ámbito de la tecnología educativa se incorporan no solo las plataformas y medios disponibles para el proceso de enseñanza aprendizaje, sino los recursos diseñados para abordar las necesidades e intereses de los estudiantes en los diferentes niveles educativos.

En el nivel de Educación Inicial, dada la variedad de aprendizajes esperados en las distintas áreas, el uso de recursos y materiales tecnológicos tiene un gran potencial para elevar la calidad de la enseñanza y diversificar las experiencias que se propician en el aula (De Caso, Blanco y Navas, 2012). Asimismo, diferentes autores coinciden en la importancia de su pronta incorporación en el proceso de enseñanza aprendizaje desde edades tempranas, puesto que en ellas se desarrollan las bases de la personalidad (Cabero, 1996; Martínez, 2010; Fernández, 2017). Para ello, es necesario en primer lugar tanto la dotación de infraestructura y recursos que apoyen su uso en las instituciones educativas, como el adecuado manejo de los mismos por parte de los responsables educativos, sobre todo los docentes, quienes con sus competencias digitales pueden ser capaces de generar materiales para 
apoyar el proceso de enseñanza aprendizaje. No solo se trata de implementar algún recurso tecnológico para "modernizar" la práctica, sino que el uso de materiales tecnológicos forma parte integral del proceso de enseñanzaaprendizaje, e "incluirlas en las unidades o proyectos, abordando temas que satisfagan las necesidades e intereses de los niños y niñas fortaleciendo los conocimientos obtenidos" (Zevallos, 2018, p.54).

Con respecto al primer aspecto, en Venezuela se adoptaron algunas medidas orientadas al reconocimiento de la tecnología como factor clave de desarrollo, sin embargo, las políticas realmente efectivas han sido pocas, pues continua la existencia de brechas digitales; como en efecto, expone la investigación de Bracho (2017). En ella, el autor asegura que persisten problemas en el escenario venezolano relacionados con el acceso a internet, manejo del computador por parte del docente, falta de formación a los mismos y resistencia a utilizar la tecnología en pro del aprendizaje de los alumnos, entre otros; lo cual ha producido el rezago del país en comparación con otros países de la región, aun cuando en América Latina el acceso, uso y apropiación de las tecnologías es muy limitado (UNESCO, 2017).

La problemática descrita, coincide con el contexto de estudio la Parroquia Juárez, una zona aledaña a la ciudad de Barquisimeto, Estado Lara, Venezuela, en la cual existe poco acceso a internet en la comunidad, aunado a las carencias propias de la zona en cuanto a otros servicios básicos. Es importante además mencionar que en dicha comunidad se encuentra disponible un Centro Bolivariano de Informática y Telemática (CBIT) en el que la comunidad y la escuela pueden participar en estrategias formativas basadas en la TIC, pero la distancia geográfica entre el CBIT y algunos de los centros educativos impide que los niños y docentes puedan dirigirse a ellos en forma de grupo-clase. Asimismo, la observación y entrevistas informales con docentes de aula del sector, a partir de la práctica pedagógica de maestras y académicas, muestran que existe resistencia a la incorporación de recursos y materiales tecnológicos educativos y prefieren el uso de recursos de material didáctico concreto en el proceso de enseñanza, no solo por una razón actitudinal del docente sino porque la mayoría de instituciones solo cuentan con televisores y equipos de reproducción básicos, que no son aprovechados para el proceso de aprendizaje.

Esta situación hace pensar en la relevancia de optimizar los recursos que se encuentren en las instituciones y cómo contribuir con una educación de calidad a pesar del contexto desfavorecedor descrito, con el ánimo de proveer herramientas a los docentes para facilitar la mediación de los aprendizajes en la educación inicial. Desde esta perspectiva, existen tres 
áreas de aprendizaje en las cuales se organizan los aprendizajes esperados de los niños: Formación Personal y Social, Comunicación y Representación y Relación con el Ambiente.

Con respecto a esta última, investigaciones regionales han detectado que lo relacionado al Componente Características, Cuidado y Preservación del Ambiente se caracteriza por una escasez de recursos y materiales didácticos específicos (Túa, 2009; Herrera, 2011; León, 2013; Colmenárez, 2015); siendo ésta un área que demanda de los docentes mayor organización didáctica, pues requiere experiencias de aprendizaje específicas que ubiquen al niño en su entorno físico y natural para que explique los fenómenos o situaciones ambientales a través de la observación, formulación de hipótesis, experimentación y comprobación, además de desarrollar "capacidades efectivas y valorativas como ser integrante del ambiente" (MED, 2005, p. 29).

Desde esta perspectiva la investigación se justifica, pues propone como uno de los materiales tecnológicos en el nivel de Educación Inicial, etapa preescolar (3-6 años) el uso de micros audiovisuales, los cuales pueden transmitir conocimientos significativos y mensajes sensibilizadores acerca del área Relación con el Ambiente y desarrollar las capacidades visuales, cognitivas, auditivas y lingüísticas de los niños (Maza, 1997), así como su conciencia ecológica. Además, creemos que los micros audiovisuales representan un recurso accesible en contextos tan vulnerables como en los que se ha hecho el estudio y pueden ser utilizados por los docentes con los equipos tecnológicos que cuentan.

Maza (1997) define los micros audiovisuales como un producto híbrido, que permite transmitir un mensaje informativo, educativo (o ambiental en este caso) a través de un sistema de captación y reproducción instantánea del mensaje, la imagen y el sonido, con una duración de tiempo que oscila de un minuto a cinco minutos. Los micros audiovisuales enriquecen los entornos de aprendizaje e introducen nuevas formas de expresión y de registro de la realidad en los ambientes escolares de los infantes (Semenderiadis y Martidou, 2009). Asimismo, los recursos audiovisuales para niños preescolares ponen en funcionamiento diferentes habilidades como la percepción, entendiendo que a esta edad los niños están más atentos a lo que ven que al significado en sí, el cual construyen progresivamente si el contenido se ajusta a su edad y aumenta su experiencia emocional (Yazar y Arifoglu, 2012).

En este sentido, los micros audiovisuales, pueden servir de mediadores instrumentales para presentar información a los niños de la etapa preescolar de forma organizada para desarrollar su nivel de pensamiento (Schneuwly y Bronckart, 2012), en el marco de los aprendizajes esperados establecidos en el diseño curricular. 
Así, el objetivo general del estudio fue proponer los micros audiovisuales para mediar los aprendizajes relacionados al cuidado y preservación del ambiente. Para ello se plantearon como objetivos específicos: determinar el uso de los micros audiovisuales en los docentes de la etapa preescolar y con base en el diagnóstico, diseñar el material y validarlo.

\subsection{Componente características, cuidado y preservación del Ambiente en Preescolar}

La Educación Inicial en Venezuela se refiere al nivel educativo que atiende a los niños entre 0 y 6 años, y es contentivo de dos etapas específicas: maternal (0-3 años) y preescolar (3-6 años). Esta última, comprende las edades en las cuales se enfatiza la atención pedagógica con experiencias de aprendizaje cónsonas a las diferentes áreas curriculares: Formación Personal y Social, Comunicación y Representación y Relación con el Ambiente; mismas que requieren un docente activo y reflexivo de su quehacer para poner en práctica una enseñanza desde un enfoque lúdico, afectivo y que fomente el desarrollo intelectual de los niños.

Por ello se plantean dentro de las áreas, unos componentes los cuales "determinan los elementos que se deben trabajar y profundizar para que los niños y las niñas avancen en su desarrollo y aprendizaje" (MED, 2005, p. 77). Para efectos del presente estudio se aborda el componente curricular Características, Cuidado y Preservación del Ambiente como el conjunto de saberes a lograr en los niños, los cuales están relacionados con el medio ambiente.

Tabla 1. Matriz descriptiva del componente Características, Cuidado y Preservación del Ambiente

\begin{tabular}{lc}
\hline \multicolumn{1}{c}{ Objetivo del componente } & Aprendizajes esperados para la etapa preescolar \\
\hline $\begin{array}{l}\text { Identificar los elementos } \\
\text { del entorno, explicándo- }\end{array}$ & Que el niño y la niña aprendan a: \\
se progresivamente los & - Reconocer algunas características morfológicas de los seres \\
acontecimientos sociales & vivos. \\
y naturales a través de la & Reconocer algunos beneficios que proporcionan las plantas \\
observación, formulación & y los animales. \\
$\begin{array}{l}\text { de hipótesis, la experimen- } \\
\text { tación y la comprobación, }\end{array}$ & Realizar prácticas que contribuyan a preservar el ambiente. \\
desarrollando capacidades & Fos meteorológicos. \\
efectivas y valorativas como & - Participar en el cuidado de los seres vivos de su entorno \\
ser integrante el ambiente. & familiar, escolar y comunitario. \\
& - Reconoce algunos agentes contaminantes del ambiente.
\end{tabular}

Fuente: Elaboración propia a partir del Currículo de Educación Inicial (MED, 2005). 
En el currículo de Educación Inicial (MED, 2005) este componente asume los aprendizajes que se relacionan con descubrir, conocer, comprender y poner en práctica acciones para el cuidado del ambiente (plantas, animales, fenómenos naturales y la interacción entre los elementos del mismo), como objetivo y aprendizajes esperados.

\subsection{Tecnología educativa: Los microsaudiovisuales}

La incorporación de la tecnología, en el ámbito educativo según Briceño (2015), representa en el niño y la niña una nueva forma de adquirir conocimiento, permitiendo crear procesos de enseñanza y aprendizaje, que los lleven a la construcción de un aprendizaje significativo, a partir de experiencias reales y virtuales con una intencionalidad pedagógica, debido a que tiene particular relevancia en mejorar la calidad de los procesos educativos. En el caso de los micros audiovisuales, Maza (1997) asegura que como producción audiovisual puede transmitir un mensaje educativo según el propósito del docente, por ello Pere (2003) plantea que deben considerarse tres elementos:

El mensaje: es la idea a transmitir. Con ella se crea el guión y se incorporan los otros elementos (imagen ysonido).

La imagen: Es la representación gráfica que permite ser relacionada con el mensaje a transmitir yactiva en los niños los procesos de pensamiento, percepción y memoria para comunicar sentidos de manera atractiva la información educativa.

El sonido: que atrapa la atención del infante y lo sitúa en un contexto al recrear y describir la situación que se observa en la imagen, a través de la música, la palabra y otros efectos sonoros.

Figura 1: Elementos de los micros audiovisuales.

Fuente: Elaboración propia a partir de Pere (2003).

Asimismo, es importante conocer los tipos de micros audiovisuales, para que el docente pueda otorgarle la intención pedagógica pertinente, acorde a los aprendizajes a lograr por los niños. A saber:

- Monoconceptual: se centra en presentar un concepto determinado para los infantes y es de corta duración. Por ejemplo: la ballena, el perro.

- Lección temática: propone presentar de manera sistemáticay con una profundidad adecuada y gradual un tema en concreto a los 
destinatarios. Es un poco más amplio que el monoconceptual, por ejemplo: animales vertebrados, ciclo del agua.

- Narrativo: muestra una trama narrativa a través de la cual se va presentando la información relevante para los infantes con una historia y personajes. Por ejemplo: Luis visita el zoológico.

- Motivadores: pretenden impactar, motivar e interesar a los espectadores de un tema. En el caso de los niños, suele utilizarse canciones e imágenes animadas. Por ejemplo: la Canción del cuidado de las plantas.

Es importante mencionar, que los materiales de aprendizaje que conjugan el mensaje junto a lo visual (imagen y auditivo (sonido) suelen captar la atención de los niños y lo predisponen a asumir diferentes conductas cognitivas ante la información presentada, lo que permitiría ver la progresión de los aprendizajes e incluso de la motivación a aprender (Olube, 2015).

\section{Métodos y materiales}

En lo concerniente al tipo de investigación, ésta se distingue como cuantitativa ya que utiliza como base de análisis la estadística a través de un planteamiento claro y delimitado del problema a investigar (Hernández, Fernández y Baptista, 2006). Se considera además una investigación de campo, pues la información es recogida directamente de donde ocurren los hechos (Sabino, 2002), y es una investigación descriptiva que "busca especificar las propiedades, características y perfiles importantes de personas, grupos, comunidades o cualquier otro fenómeno que sea sometido a análisis". (Hernández, Fernández y Baptista, 2006, p. 217). En este caso se busca diagnosticar el uso de los micros audiovisuales por parte de los docentes de Educación Inicial para detectar si existe la necesidad de diseñar una propuesta. En atención a los objetivos propuestos, se establecieron 3 fases de investigación: Diagnóstico, Diseño y Validación de la propuesta.

\subsection{Fase I. Estudio diagnóstico}

Para Cerda (2004) "el diagnóstico es un procedimiento que permite conocer de manera objetiva la realidad que es de interés al investigador" (p. 8). Esta fase permitió determinar la necesidad existente de proponer la producción y recopilación de los micros audiovisuales educativos para la mediación de los aprendizajes del componente "Características, Cuidado y Preservación del Ambiente" en niños y niñas de edad preescolar en los 
Centros de Educación Inicial de la Parroquia Juárez. En tal sentido, la parte diagnóstica permitió determinar dicha necesidad para la cual se realizó una revisión de la bibliografía pertinente a la temática, luego se diseñó un cuestionario para recopilar la información necesaria y satisfacer los objetivos planteados en el estudio.

\section{Población}

Los sujetos de estudio para la presente investigación la constituyeron 38 docentes que laboran en los centros de Educación Inicial de la Parroquia Juárez, Estado Lara; lo cual constituye el cien por ciento (100\%) de la población objeto de estudio y se tomó toda por considerarla pertinente y representativa para el caso planteado.

Tabla 2. Distribución de los sujetos de estudios

\begin{tabular}{ll}
\hline \multicolumn{1}{c}{ Centros de Educación Inicial } & Cantidad de docentes \\
\hline Boyuare & Ocho (8) \\
Mis Travesuras & Ocho (8) \\
Juan Pablo II & Ocho (8) \\
Antonio Ricaurte & Ocho (8) \\
NER 139 & Seis (6) \\
Total & Treinta y ocho (38) \\
\hline
\end{tabular}

Fuente: Elaboración propia.

\section{Instrumento de recolección de datos}

El instrumento utilizado fue un cuestionario con preguntas cerradas, en el que se establecen previamente las opciones de respuestas elegibles por el encuestado. Dicho instrumento consta de 12 ítems, que pretenden determinar la utilización efectiva en el aula de micros audiovisuales a través de una escala de frecuencia con las opciones siempre, algunas veces y nunca, en la cual el encuestado escoge solo una opción.

Para la validez de contenido del instrumento se contó con 3 profesionales: 2 especialistas en Educación Inicial y 1 metodólogo, quienes consideraron la adecuación, pertinencia y claridad de los ítems, así como su relación con los objetivos y la revisión documental del estudio. La confiabilidad se obtuvo a través del Alpha de Cronbach y dio como resultado 0.89, lo que indica una alta consistencia interna.

Es importante mencionar que los docentes sujetos del estudio, aceptaron explícitamente participar en la investigación con la salvaguarda de sus datos personales, así como hubo una carta de aceptación firmada y sellada por el directivo de las instituciones en las cuales laboraban. 


\section{Análisis de datos}

Una vez recopilada la información a través del cuestionario se procedió a su organización, luego fueron procesados siguiendo las técnicas de la estadística descriptiva, para ello se utilizó el Software SPSS en su versión Statistics 26.0.

\section{Resultados}

Como se puede constatar en la gráfica 1 ítem 1 , un 44,73\% de las docentes que participaron en esta investigación expresaron nunca usar los micros cortos para dar a conocer al niño y a la niña conceptos relacionados al ambiente, el $28,94 \%$ siempre y un $26,31 \%$ algunas veces lo usan. En el ítem2, un 55,26\% manifestaron que nunca emplean el micro de corta duración para que los infantes tengan noción del ciclo de vida en los seres vivos, mientras que el $23,68 \%$ algunas veces y un $21,5 \%$ siempre lo emplean.

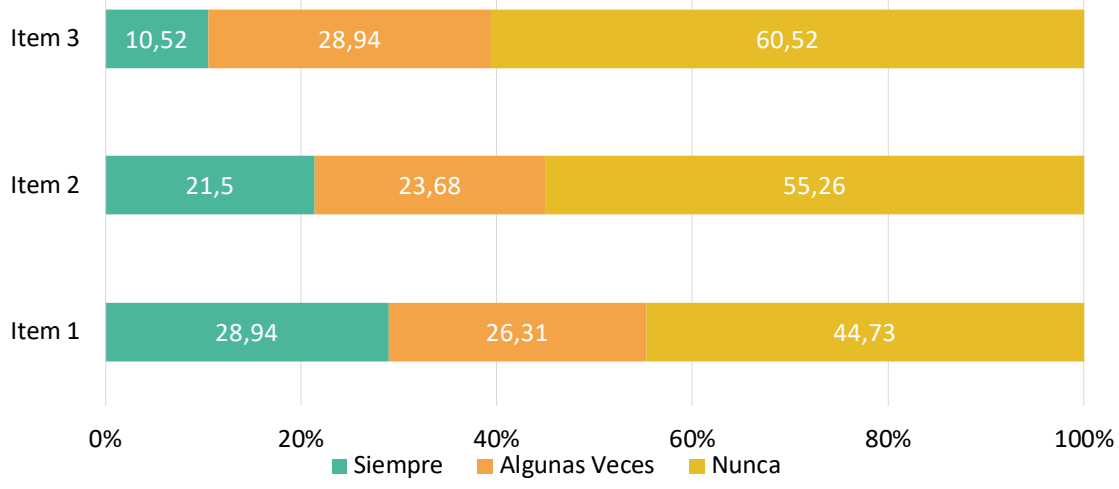

Gráfica 1. Respuestas de los sujetos de estudio en cuanto a la Dimensión: Uso de los tipos de micros audiovisuales para la mediación de aprendizajes. Indicador: Monoconceptual. Fuente: Cuestionario aplicado a docentes.

Asimismo, en el ítem 3, un 60,52\% de los encuestados expresaron que nunca le facilitan al estudiante micros para conocer las características morfológicas de los seres vivos, un $28,94 \%$ opinan que algunas veces y un $10,52 \%$ siempre lo facilitan. Las respuestas presentadas revelan que los docentes en su mayoría no utilizan micros audiovisuales para presentar conceptos relacionados a los aprendizajes esperados en el componente de Cuidado del Ambiente. 


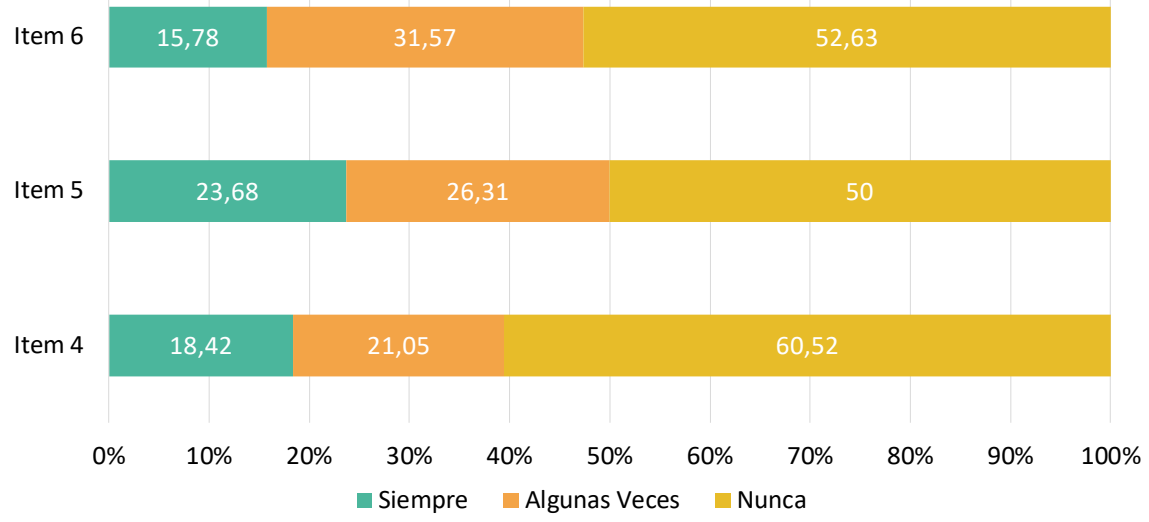

Gráfica 2. Respuesta de los sujetos de estudio en cuanto a la Dimensión: Uso de los tipos de micros audiovisuales para la mediación de aprendizajes. Indicador: Lección Temática. Fuente: Cuestionario aplicado a docentes.

Se puede evidenciar en la gráfica 2 ítem 4, que el 60,52\% de las encuestadas expresaron que nunca utilizan el micro como una lección temática para mostrar a los infantes que tengan una concepción de la ontogénesis de los seres vivos; un $21,05 \%$ algunas veces y el $18,42 \%$ siempre lo utilizan. En el ítem 5, un 50\% manifestaron que nunca presentan de manera sistemática micros para saber la clasificación de los seres vivos, mientras que el $26,31 \%$ algunas veces y el $23,68 \%$ siempre lo presentan. Del mismo modo, en el ítem 6 , un $52,63 \%$ de los encuestados expresaron que nunca muestran micros a los niños relacionados a los beneficios que proporcionan las plantas o los animales, un $31,57 \%$ opinan que algunas veces y el 15 , $78 \%$ siempre lo muestran.

Los resultados indican que la lección temática, es un tipo de micro audiovisual usado con mínima frecuencia en la etapa preescolar, por lo tanto los niños tienen pocas posibilidades de aprender acerca de aspectos como el desarrollo de los seres vivos, su clasificación o incluso de las bondades de las plantas y animales en la alimentación, salud y otras necesidades humanas.

Se observa en la gráfica 3 ítem 7, que el 52,63\% de los sujetos que participaron en la investigación, señalaron que nunca emplean micros con una trama narrativa para establecer criterios de las prácticas, que contribuyan a preservar el ambiente, mientras el $31,57 \%$ siempre lo emplean y el $15,78 \%$ algunas veces. En el ítem 8, un 63,15\% de los encuestados manifestaron que nunca muestran al estudiante micros narrativos para comprender el origen de algunos fenómenos meteorológicos, el 21,05\% señalaron que siempre, mientras que el $15,78 \%$ algunas veces se lo muestra. En cuanto al ítem 9 , el 52, 63\% 
opinó que nunca promueve micros que describen los agentes contaminantes para percatarse del impacto negativo que han ocasionado al planeta, el 26, $31 \%$ expresó que algunas veces lo promueven y un $21,05 \%$ siempre.

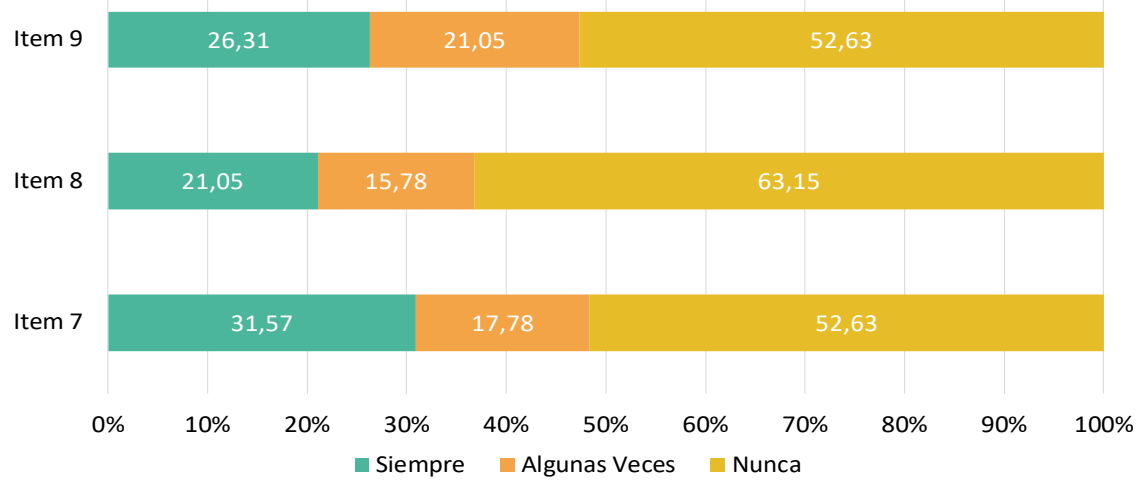

Gráfica 3. Respuesta de los sujetos de estudio en cuanto a la Dimensión: Uso de los tipos de micros audiovisuales para la mediación de aprendizajes. Indicador: Narrativo.

Fuente: Cuestionario aplicado a docentes.

Con respecto al uso de micros narrativos en la etapa preescolar, las docentes en su mayoría no aplican este recurso en su didáctica de clase, por lo cual se dejan a un lado conocimientos relacionados a las buenas prácticas ambientales y a los fenómenos meteorológicos, aspectos que son importantes para que los niños reconozcan los hechos naturales, formulen hipótesis y construyan progresivamente conceptos del ambiente.

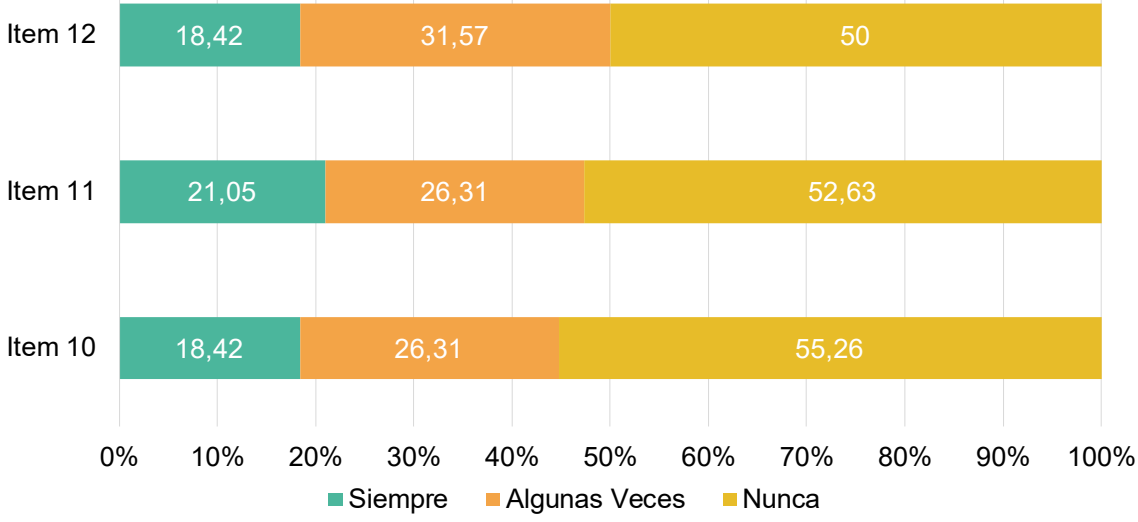

Gráfica 4. Respuesta de los sujetos de estudio en cuanto a la Dimensión: Uso de los tipos de micros audiovisuales para la mediación de aprendizajes. Indicador: Motivadores. Fuente: Cuestionario aplicado a docentes. 
Cabe afirmar, que en la gráfica 4 en la Dimensión: Uso de los tipos de micros audiovisuales para la mediación de aprendizajes. Indicador: Motivadores en el ítem 10, el 55,26\% de los docentes encuestados señalaron que nunca usan micros relacionados a los recursos naturales, mientras el 26, $31 \%$ opinan que algunas veces lo usan y el 18,42\% siempre. En el ítem, 11 un $52,63 \%$ de las docentes manifestaron que nunca implementan micros para conocer el cuidado de la biodiversidad de las especies que motive al niño y la niña salvar el planeta, un $26,31 \%$ señaló que siempre, mientras que el $21,05 \%$ algunas veces se lo implementan. De igual modo, en el ítem 32 , el $50 \%$ opinó que nunca utilizan micros que impulse en el estudiante comprender la importancia del reciclaje, un $31,57 \%$ expresó que algunas veces y un $18,42 \%$ siempre lo usan.

Finalmente, los resultados hacen inferir que los docentes encuestados en su mayoría no utilizan los micros audiovisuales para mediar los aprendizajes relacionados al conocimiento, cuidado y preservación del ambiente desde la Educación Inicial, y solo en puntuales casos lo utilizan algunas veces. Tomando en cuenta los diferentes tipos de micros audiovisuales, también se observa que los valores más altos de la respuesta "nunca" se encuentran en el uso de micros de tipo monoconceptual $(60,52 \%)$ para que los niños reconozcan características morfológicas de los seres vivos, $60,52 \%$.

\subsection{Fase II. Diseño de la Propuesta}

Luego de los resultados obtenidos en la Fase I, y en vista de la necesidad detectada se procedió a denominar la propuesta para hacerla más atractiva a niños y docentes, lo cual resultó en el título "Aprender sobre el ambiente". Seguidamente, se hizo la producción y recopilación de los micros audiovisuales, considerando las características de los niños, el currículo del nivel de Educación Inicial y el escenario en el cual se estaba generando la investigación. De allí, fue importante definir el objetivo de la propuesta para luego proceder a su elaboración a través de una programación organizada de los micros audiovisuales.

Para ello, se consideraron los tipos de micro (monoconceptual, lección temática, narrativo y motivador) en cuanto a los contenidos a trabajar y se hicieron los ajustes pertinentes, en lo que podríamos denominar la adecuación didáctica, es decir, pertinencia recurso-contenido. 


\section{Objetivo de la propuesta "Aprender sobre el Ambiente"}

Facilitar a las docentes micros audiovisuales como material tecnológico educativo para la mediación de los aprendizajes del componente Características, Cuidado y Preservación del Ambiente en niños de la etapa preescolar (3- 6 años).

\section{Programación y sus etapas}

La presente propuesta se realizó con una revisión minuciosa del Currículo de Educación Inicial (MED, 2005) en relación con los aprendizajes del componente mencionado, en el cual se destacan: características morfológicas de los seres vivos, beneficios que proporcionan las plantas y los animales, prácticas que contribuyan a preservar el ambiente, origen de algunos fenómenos meteorológicos, cuidado de los seres vivos de su entorno familiar, escolar y comunitario; así como, prevenir los agentes contaminantes que deterioran el planeta.

Posteriormente, para la programación de los micros se transitaron tres etapas:

- Pre-producción: donde se realiza una investigación y planificación del tema a tratar o el mensaje que se desea transmitir, además se crea el guión.

- Producción: la cual consiste en la grabación según lo planificado. Para ello se utilizó la voz de una de las investigadoras.

- Post-producción: en la que selecciona el material grabado según el guión y luego se edita, utilizando los programas Microsoft Power Point y Windows MovieMaker 2.6, con una clara intencionalidad pedagógica, que capte la atención de la audiencia, calidad del mensaje, la imagen y el sonido para mediar un aprendizaje significativo y enriquecer la relación con el ambiente.

\section{Descripción de la programación}

La programación está conformada por 12 micros audiovisuales, producidos y recopilados -3 de cada tipo (monoconceptual, lección temática, narrativos y motivadores)-, los cuales se grabaron en formato CD incorporando los hipervínculos respectivos y organizando de forma lógica las pantallas, de manera que el docente pueda seleccionar el micro audiovisual de su preferencia. Los mismos, pueden convertirse en la actividad generadora de una situación de aprendizaje más amplia, dirigida a los niños en edad preescolar de forma tal que obtengan los aprendizajes como un conjunto de saberes esenciales para un desarrollo de forma integral y globalizada, bajo una visión 
holística que los conlleve al respeto por la conservación del ambiente. Se presenta a continuación una muestra del índice que aparece en la pantalla de inicio, con los tipos de micros y el aprendizaje-tema a trabajar:

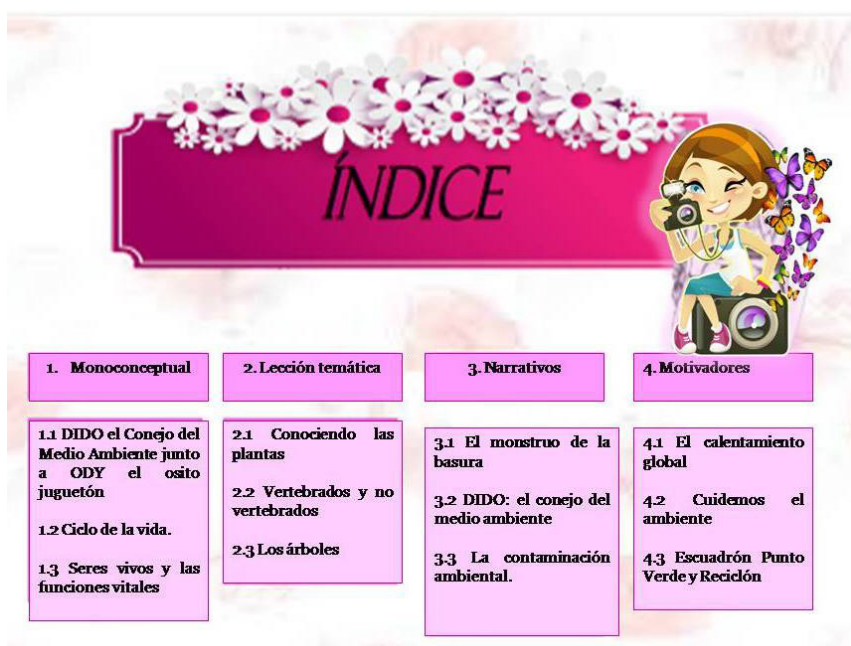

Figura 2. Pantalla de inicio con el índice de los micros audiovisuales.

Fuente: Elaboración propia.

Asimismo, se puede observar las pantallas de cada tipo de micro (figura 3). En este caso se muestra los tipos monoconceptuales, a los cuales puede acceder al docente con un solo click.

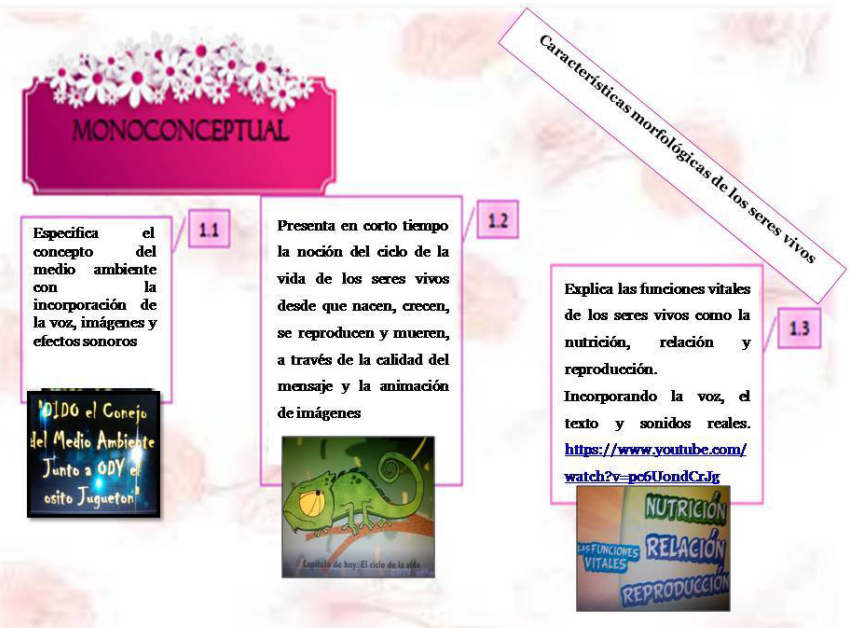

Figura 3. Pantalla de los micros de tipo monocenceptuales.

Fuente: Elaboración propia. 
La adaptabilidad de los micros audiovisuales como recurso tecnológico educativo se proyecta para una audiencia infantil, profesionales en educación, especialistas, padres, madres o responsables del proceso educativo u otros entes interesados en desarrollar el amor y el respeto por la naturaleza a través de una propuesta creativa, interesante e innovadora.

Asimismo, los micros audiovisuales diseñados son un aporte al docente en su desarrollo profesional, al promover su acción pedagógica y ser apoyo para la mediación del proceso educativo, mismo que conlleve a la construcción de una conciencia particular y colectiva del niño y la niña. Un proceso dirigido hacia la formación de actitudes positivas de cuidado y preservación ambiental, y el reconocimiento de la realidad natural de la cual también es un ser integrante. En atención a lo planteado, durante la ejecución de la programación el docente debe considerar los siguientes aspectos:

1. Presentación: la cual incluye mantener el título "Aprender sobre el ambiente" en cada actividad, como una sección o momento de diversión y aprendizaje para los niños. Allí, el docente expresa la información precisa acerca de lo que se va a presentar en la pantalla antes de la proyección del micro. Por ello, debe considerar las características del auditorio, la audiencia, emplear la terminología adecuada, elconocimiento e interés sobre el tema y captar la atención. Proponemos, en este caso el uso de consignas y frases cantadas muy breves que le inviten a mantener su atención en la actividad.

2. Condiciones para la proyección del micro audiovisual: referidas a cuántas veces, de qué forma, en qué condiciones y en qué momento el docente va a presentar el micro audiovisual. Todas estas alteraciones, durante la proyección del micro audiovisual, obedecerán a motivos concretos que deben quedar perfectamente claros para la audiencia. No es lo mismo presentar un micro al inicio de una jornada escolar de los niños de preescolar, que al final de dicha jornada, cuando el docente no cuenta con tiempo suficiente para hacer las mediaciones pertinentes y adecuadas del aprendizaje a lograr.

3. Actividades a desarrollar por el niño y la niña: es importante que los niños sean participantes activos de su propio proceso de aprendizaje y así, romper la pasividad receptiva de algunas aulas, esto con el propósito de lograr la asimilación y comprensión del contenido a trabajar. Por ello, es necesario que el docente 
proponga actividades antes, durante o después de la proyección del micro audiovisual como: literarias, gráfico-plásticas, artísticas y ecológicas que lo ayuden en la mediación del aprendizaje.

4. Actividades a desarrollar por el docente: Hará la introducción del momento de "Aprender sobre el ambiente como se ha mencionado y presentaráel micro audiovisual relacionado a los aprendizajes del componente Características, Cuidado y Preservación del Ambiente, así como las aclaraciones previas que estime necesarias. Además, motivará a los niños y niñas para que permanezcan atentos y, una vez terminada la proyección, organizará y coordinará círculos de conversación con preguntas divergentes que le permita al niño y a la niña expresar sus ideas, aclarar las dudas o compartir las experiencias vividas. También debe proponer situaciones de observación y experimentación que les permitan a los niños asimilar la información y continuar haciéndose preguntas que le lleven a seguir descubriendo el ambiente. A continuación la programación propuesta:

Tabla 3. Programación del material tecnológico

\begin{tabular}{|c|c|c|c|}
\hline $\begin{array}{l}\text { Tipo de micro } \\
\text { audiovisual }\end{array}$ & $\begin{array}{c}\text { Aprendizajes } \\
\text { esperados }\end{array}$ & $\begin{array}{c}\text { Datos del micro } \\
\text { audiovisual }\end{array}$ & Descripción \\
\hline \multirow[t]{3}{*}{ Monoconceptual } & $\begin{array}{l}\text { Reconocer las } \\
\text { características } \\
\text { morfológicas de } \\
\text { los seres vivos. }\end{array}$ & $\begin{array}{l}\text { DIDO el conejo del } \\
\text { Medio Ambiente } \\
\text { junto a ODY el osito } \\
\text { juguetón. } \\
\text { Duración: } 4,35 \mathrm{~min} \text {. } \\
\text { Elaboración propia. }\end{array}$ & $\begin{array}{l}\text { Especifica el concepto del } \\
\text { medio ambiente con la incor- } \\
\text { poración de la voz, imágenes y } \\
\text { efectos sonoros. }\end{array}$ \\
\hline & & $\begin{array}{l}\text { Ciclo de la vida. } \\
\text { Recopilación: El ca- } \\
\text { maleón y las ciencias } \\
\text { naturales } \\
\text { Duración: 3,25 min. }\end{array}$ & $\begin{array}{l}\text { Presenta en corto tiempo la } \\
\text { noción del ciclo de vida de } \\
\text { los seres vivos desde que na- } \\
\text { cen, crecen, se reproducen y } \\
\text { mueren, a través de la calidad } \\
\text { del mensaje y la animación de } \\
\text { imágenes }\end{array}$ \\
\hline & & $\begin{array}{l}\text { Seres vivos y las fun- } \\
\text { ciones Vvitales. } \\
\text { Recopilación: Ha- } \\
\text { ppyLearning } \\
\text { Duración: 5,00 min. }\end{array}$ & $\begin{array}{l}\text { Explica las funciones vitales de } \\
\text { los seres vivos como la nutri- } \\
\text { ción, relación y reproducción. } \\
\text { Incorporando la voz, el texto y } \\
\text { sonidos reales. }\end{array}$ \\
\hline
\end{tabular}




\begin{tabular}{|c|c|c|c|}
\hline $\begin{array}{l}\text { Tipo de micro } \\
\text { audiovisual }\end{array}$ & $\begin{array}{l}\text { Aprendizajes } \\
\text { esperados }\end{array}$ & $\begin{array}{l}\text { Datos del micro } \\
\text { audiovisual }\end{array}$ & Descripción \\
\hline \multirow[t]{10}{*}{$\begin{array}{l}\text { Lección Temá- } \\
\text { tica }\end{array}$} & \multirow{7}{*}{$\begin{array}{l}\text { Reconocer las } \\
\text { características } \\
\text { morfológicas de } \\
\text { los seres vivos }\end{array}$} & $\begin{array}{l}\text { Conociendo las plan- } \\
\text { tas. }\end{array}$ & \multirow{3}{*}{$\begin{array}{l}\text { Presenta de manera sistemática } \\
\text { el conocimiento de las plantas } \\
\text { en reconocer sus partes: raíz, } \\
\text { tallo, hojas, flores y frutos, el } \\
\text { significado de la fotosíntesis y } \\
\text { su importancia como alimento. } \\
\text { Con imágenes animadas del } \\
\text { Docente, niño y niña. }\end{array}$} \\
\hline & & $\begin{array}{l}\text { Recopilación: Aula } \\
365\end{array}$ & \\
\hline & & Duración: 3,15 min. & \\
\hline & & Vertebrados & \multirow{4}{*}{$\begin{array}{l}\text { Muestra la clasificación de los } \\
\text { seres vivos en Vertebrados (ma- } \\
\text { míferos, aves, peces, reptiles y } \\
\text { anfibios) y los no vertebrados } \\
\text { con protección corporal y sin } \\
\text { protección corporal como las } \\
\text { características más relevantes } \\
\text { de cada uno, que conecta la } \\
\text { información que se desea co- } \\
\text { municar con la realidad. }\end{array}$} \\
\hline & & Duración: 4,06 min. & \\
\hline & & Duración: 4,09 min. & \\
\hline & & $\begin{array}{l}\text { Recopilación: El ca- } \\
\text { maleón y las ciencias } \\
\text { naturales }\end{array}$ & \\
\hline & \multirow{3}{*}{$\begin{array}{l}\text { Beneficios que } \\
\text { proporcionan } \\
\text { las plantas y } \\
\text { los animales. }\end{array}$} & Los Árboles. & \multirow{3}{*}{$\begin{array}{l}\text { Explica paso a paso la impor- } \\
\text { tancia de los árboles en el } \\
\text { planeta tierra y para todos los } \\
\text { seres vivos, captando por medio } \\
\text { de imágenes la realidad del } \\
\text { entorno natural. }\end{array}$} \\
\hline & & $\begin{array}{l}\text { Recopilación: Ha- } \\
\text { ppyLearning }\end{array}$ & \\
\hline & & Duración: 4,20 min. & \\
\hline \multirow[t]{8}{*}{ Narrativos } & \multirow{3}{*}{$\begin{array}{l}\text { Prácticas que } \\
\text { contribuyan } \\
\text { a preservar el } \\
\text { ambiente }\end{array}$} & $\begin{array}{l}\text { El monstruo de la } \\
\text { basura. }\end{array}$ & \multirow{3}{*}{$\begin{array}{l}\text { Muestra a través de una trama } \\
\text { narrativa con imágenes anima- } \\
\text { das y efectos sonoros los daños } \\
\text { que ocasionan al planeta por } \\
\text { la acumulación de la basura, e } \\
\text { invita a organizar prácticas para } \\
\text { preservar el ambiente como un } \\
\text { guardián de los bosques. }\end{array}$} \\
\hline & & $\begin{array}{l}\text { Recopilación: Conaf- } \\
\text { minagri }\end{array}$ & \\
\hline & & Duración: 3,33 min. & \\
\hline & \multirow{2}{*}{$\begin{array}{l}\text { Origen de algu- } \\
\text { nos fenómenos } \\
\text { meteorológicos. }\end{array}$} & $\begin{array}{l}\text { Dido: el conejo del } \\
\text { medio ambiente. }\end{array}$ & \multirow{2}{*}{$\begin{array}{l}\text { Presenta información rele- } \\
\text { vante de los fenómenos me- } \\
\text { teorológicos como: la lluvia, } \\
\text { relámpagos, truenos, arco iris, } \\
\text { niebla, nieve, viento huracán y } \\
\text { la sequía incorporando la voz y } \\
\text { sonidos que recrea el ambiente } \\
\text { descrito por las imágenes. }\end{array}$} \\
\hline & & $\begin{array}{l}\text { Duración: 4,22 min. } \\
\text { Elaboración propia }\end{array}$ & \\
\hline & \multirow{3}{*}{$\begin{array}{l}\text { Agentes conta- } \\
\text { minantes del } \\
\text { ambiente }\end{array}$} & $\begin{array}{l}\text { La contaminación } \\
\text { ambiental. }\end{array}$ & \multirow{3}{*}{$\begin{array}{l}\text { Narra ¿qué es la contaminación } \\
\text { ambiental?, los agentes conta- } \\
\text { minantes (físicos, químicos y } \\
\text { biológicos) y la relación inade- } \\
\text { cuada de los seres humanos } \\
\text { en provocar impactos negativos } \\
\text { que deterioran el ambiente. }\end{array}$} \\
\hline & & $\begin{array}{l}\text { Recopilación: Aula } \\
365\end{array}$ & \\
\hline & & $\begin{array}{l}\text { Duración: 4,07 min. } \\
\text { Elaboración propia }\end{array}$ & \\
\hline
\end{tabular}




\begin{tabular}{|c|c|c|c|}
\hline $\begin{array}{l}\text { Tipo de micro } \\
\text { audiovisual }\end{array}$ & $\begin{array}{l}\text { Aprendizajes } \\
\text { esperados }\end{array}$ & $\begin{array}{l}\text { Datos del micro } \\
\text { audiovisual }\end{array}$ & Descripción \\
\hline \multirow[t]{9}{*}{ Motivadores } & \multirow{9}{*}{$\begin{array}{l}\text { Cuidado de los } \\
\text { seres vivos de } \\
\text { su entorno fa- } \\
\text { miliar, escolar y } \\
\text { comunitario }\end{array}$} & $\begin{array}{l}\text { El calentamiento } \\
\text { global. }\end{array}$ & $\begin{array}{l}\text { Proyecta el mensaje a través de } \\
\text { imágenes animadas y la música }\end{array}$ \\
\hline & & Duración: 2,26 min. & $\begin{array}{l}\text { que impacta en la audiencia el } \\
\text { desequilibrio en los ecosiste- } \\
\text { mas y como combatir el calen- } \\
\text { tamiento global con círculo del } \\
\text { reciclaje. }\end{array}$ \\
\hline & & Canción: & \multirow{4}{*}{$\begin{array}{l}\text { Motiva a través de la imagen } \\
\text { y banda sonora cuidar el am- } \\
\text { biente y la biodiversidad de las } \\
\text { especies con amor y respeto. }\end{array}$} \\
\hline & & $\begin{array}{l}\text { Cuidemos el medio } \\
\text { ambiente. }\end{array}$ & \\
\hline & & Duración: 2,45 min & \\
\hline & & Elaboración propia & \\
\hline & & $\begin{array}{l}\text { Escuadrón Punto } \\
\text { Verde y Reciclón. }\end{array}$ & \multirow{3}{*}{$\begin{array}{l}\text { Incentiva como el círculo del } \\
\text { reciclaje permite combatir el } \\
\text { Calentamiento Global con imá- } \\
\text { genes animadas adaptadas a la } \\
\text { audiencia y calidad en la banda } \\
\text { sonora. }\end{array}$} \\
\hline & & $\begin{array}{l}\text { Recopilación: Punto } \\
\text { Verde.org. }\end{array}$ & \\
\hline & & Duración: 2,30 min. & \\
\hline
\end{tabular}

Fuente: Elaboración propia.

\subsection{Fase III. Validación de la propuesta}

Después de la producción y recopilación de los micros audiovisuales como recurso tecnológico educativo para la mediación de los aprendizajes del componente Características, Cuidado y Preservación del Ambiente en niños y niñas de la edad preescolar, se procedió a la valoración de expertos con relación al diseño de la propuesta "Aprender sobre el ambiente".

Se contó con 6 profesionales: 4 especialistas en Educación Inicial que al mismo tiempo serán beneficiarios de la propuesta, y un comunicador social. Todos ellos, evaluaron la propuesta proyectada en forma audiovisual a través de un instrumento de escala dicotómica (Si-No) y considerando 3 partes referidas a los criterios técnicos, educativos y de expresividad audiovisual. En este sentido, cada criterio es contentivo de una serie de indicadores que permitieron precisar los aspectos específicos de evaluación. Así, los 14 indicadores construidos se distribuyeron de la siguiente manera:

\section{Parte: Criterios técnicos}

1. Calidad de la presentación de los contenidos

2. Legibilidad del texto

3. Calidad de la expresión verbal

4. Calidad en la presentación de las imágenes.

5. Calidad de la banda sonora. 


\section{Parte: Criterios educativos}

1. Adaptación al contenido desarrollado.

2. Organización lógica del contenido.

3. Pertinencia del contenido para la edad de los niños.

4. Adaptabilidad del micro a la programación docente.

5. Utilidad pedagógica.

III Parte: Criterios de la expresividad audiovisual

1. Organización visual.

2. Comprensión del mensaje.

3. Relación mensaje, imagen y sonido.

4. Adaptación al medio de comunicación.

La validación del material arrojó que el 100\% de los evaluadores consideran que los criterios han sido cumplidos en su totalidad. Con respecto a la expresividad audiovisual, la especialista indicó una recomendación en cuanto a mejorar la imagen de uno de los micros que presentaba una resolución media.

\section{Discusión y conclusiones}

En cuanto a las inquietudes por las cuales emerge la presente investigación, es propicio expresar que muchos de los contextos latinoamericanos afrontan dificultades en cuanto a la disposición de recursos tecnológicos en las escuelas para apoyar los procesos de enseñanza aprendizaje, pues existe una brecha digital que parece estar expandiéndose. En similitud con nuestro contexto estudiado, investigaciones como la de Freré y Saltos (2013) encontraron varias escuelas que no tienen herramientas tecnológicas adecuadas, pues carecen de equipos computacionales e incluso de internet.

Asimismo, en el presente estudio pudimos confirmar que la mayoría de docentes no usan recursos tecnológicos como los micros audiovisuales, los cuales pudieran ser una solución viable y económica para generar experiencias de aprendizaje significativas, sobre todo en el componente referente al cuidado del ambiente, mismo que requiere una planificación y organización didáctica específica por la complejidad de algunos de sus aprendizajes esperados y de los procesos de pensamiento que requiere movilizar en la etapa preescolar. Se evidencia entonces, que la no utilización de recursos y materiales tecnológicos pone a los docentes en desventaja con sus pares y a los mismos niños al perder una experiencia valiosa en su aprendizaje. 
Al respecto, Pinto, Díaz y Alfaro (2016) en su propuesta educativa aseguran que aún no se ha incorporado realmente las tecnologías educativas al proceso de enseñanza y que esto se debe, en gran parte, a la escasa formación de los maestros y a la necesidad de transformar sus metodologías. Creemos además, que la incorporación de algún recurso tecnológico al quehacer docente constituye un avance significativo en la actualización e innovación a la cual debe responder todo docente en el siglo XXI, pues debe poseer competencias digitales básicas para diseñar él mismo algunos materiales que le den pertinencia y ofrezca alternativas de aprendizaje; idea que coincide con Lázaro, Estebanell y Tedesco (2015).

Vinculado a lo anterior, Barros y Barros (2015) plantean en su análisis reflexivo que la aplicación de cualquier recurso audiovisual en el proceso educativo permite ampliar el campo de experiencias de los estudiantes al tener la posibilidad de conocer conceptos, situaciones, culturas, entre otras, que de otra manera no pudieran ser visibilizadas por el alumnado. Con respecto, a las habilidades y competencias de los niños, el estudio de Samudra, Flynn y Wong (2019) apoya estas aseveraciones al encontrar que distintos materiales audiovisuales refuerzan el vocabulario auditivo de los niños preescolares (la palabra), sobretodo en niños preescolares con vocabularios más deficientes en contextos no favorables.

En este sentido, nuestra propuesta "Aprender sobre el ambiente" contentiva de micros audiovisuales, permite al docente la incorporación de otros elementos concretos y actividades complementarias en el desarrollo de la estrategia a través de actividades lúdicas, plásticas, narrativas, entre otras; pues, la mediación implica un acompañamiento significativo al niño para que logre cada vez aprendizajes más diferenciados a través de una enseñanza realmente efectiva. En este orden de ideas, Domínguez, Aguilar, Fernández y Lozano (2017) demostraron que, a través de recursos digitales (cuento interactivo) combinados con materiales concretos en el aula de Educación Infantil, los niños podían lograr los objetivos de aprendizaje previstos y además quedaban motivados y entusiasmados por las actividades propuestas.

Vale destacar, que la propuesta se ha comenzado a implementar en nuestro contexto de estudio y ha tenido gran aceptación por parte de los docentes, quienes incluso ofrecen ideas didácticas para complementar la misma. En este sentido, es una tarea pendiente el proceso de evaluación de su implementación a fin de mejorar y ampliar las actividades en pro del aprendizaje de nuestros niños de la etapa preescolar.

Finalmente, los docentes de las primeras edades, tenemos la responsabilidad de procurar los aprendizajes más significativos posibles en la vida de los niños, y de ofrecerles ambientes didácticos ricos y variados que 
aseguren la asimilación y construcción permanente de conocimientos. El uso de las tecnologías educativas para tal fin, es una demanda propia de la sociedad actual que exige de cada uno de nosotros más actualización y el redescubrimiento de los aprendices permanentes que somos, en cumplimiento de los fines más nobles de la formación de los niños: su desarrollo integral en armonía con el ambiente y con los otros.

\section{Referencias}

Barros, C. y Barros, R. (2015). Los medios audiovisuales y su influencia en la educación desde alternativas de análisis. Revista Universidad y Sociedad, 7(3), 26-31. Recuperado de https://bit.ly/3s3Z3ZG

Bracho, F. (2017). Sociedad de la Información y Políticas de TIC en Venezuela. TELOS, Revista de Estudios Interdisciplinarios en Ciencias Sociales, 19(2), 308-330. Recuperado de https://bit.ly/398FbvN

Briceño, B. (2015). Uso de las TIC en Preescolar: Hacia la Integración Curricular. Trabajo de Grado Presentado para optar al Título de Magister en Educación Línea Comunicación y Educación. Universidad Nacional de Colombia. Bogotá, D. C.

Cabero, J. (1996). Nuevas tecnologías, Comunicación y Educación. Revista Electrónica de Tecnología Educativa, 1, Recuperado de https://bit.ly/3hNMnBE

Cerda, K. (2004). Introducción a la Metodología de la Investigación. Tercera Edición. Caracas: Editorial Ariel.

Colmenárez, S. (2015). Estrategias Globalizadoras para potenciar el Área Relación con el Ambiente en la Etapa Preescolar de los C. E. I. Juarez, Yacural y Veragacha de la Parroquia Santa Rosa. Municipio Iribarren. Trabajo de Grado para optar al Título de Magister en Educación Mención Investigación Educacional. Trabajo de Grado no publicado. UPEL-IPB. Estado Lara. Venezuela.

De Caso, A., Blanco, J. y Navas, G. (2012). Las TICS en segundo ciclo de educación infantil. International Journal of Developmental and Educational Psychology INFAD Revista de Psicología, 1(1), 189-198. Recuperado de https://bit.ly/3s4N1z8

Domínguez, J., Aguilar, J., Fernández, J. y Lozano, M. (2017). Nuevos recursos tecnológicos para trabajar en un aula de educación infantil: El cuento interactivo considerado un recurso de aprendizaje. International Journal of Developmental and Educational Psychology, 3(1), 435-448. https://doi.org/10.17060/ijodaep.2017.n1.v3.1013

Fernández, A. (2017). Las nuevas tecnologías en la primera infancia. Trabajo fin de Máster, Universidad de Cádiz, España.

Freré, F. y Saltos, M. (2013). Materiales Didácticos Innovadores, Estrategia Lúdica en el Aprendizaje. Revista Ciencia UNEMI, 10, 25-34. Recuperado de https://bit. Iy/397mFE8

Herrera, G. (2011). Material Educativo computarizado como Recurso Didáctico dirigido a los Docentes de Educación Inicial para Orientar a los niños y niñas a la Conservación del Ambiente en los C. E. I de la Parroquia Juan de Villegas. Municipio Iribarren. 
Trabajo de Grado para optar al Título de Magister en Educación Mención Educación Inicial. Trabajo de Grado no publicado. UPEL-IPB. Estado Lara. Venezuela.

Hernández, Fernández y Baptista (2006): Metodología de la Investigación. México: Mc. Graw Hill.

Lázaro, J. Estebanell, M. y Tedesco, J. (2015). Inclusión y cohesión social en una sociedad digital. RUSC. Universities and Knowledge Society Journal, 12(2). 44-59. Recuperado de $\underline{\text { https://bit.ly/3bhCcUw }}$

León, J. (2013). Estrategias para Educación Ambiental de los niños y niñas en la etapa Preescolar de los C. E. I Yacural, Veragacha y Juárez de la Parroquia Santa Rosa. Municipio Iribarren. Trabajo de Grado para optar al Título de Magister en Educación Mención Educación Inicial. Trabajo de Grado no publicado. UPEL-IPB. Estado Lara. Venezuela.

Martínez, M. (2010). Las nuevas tecnologías en Educación Infantil. Una propuesta didáctica: Webquest. Revista DIM: Didáctica, Innovación y Multimedia, 17, 1-10. Recuperado de https://bit.ly/3pYn6Yo

Maza, M. (1997). Guión para Medios Audiovisuales. Cine, Radio y Televisión. México: Editorial Alhambra Mexicana.

MED (2005). Currículo de Educación Inicial. Ministerio de Educación y Deportes, Venezuela: MED.

Olube, F. (2015). Primary School Pupils' Response to Audio-Visual Learning Process in PortHarcourt. Journal of Education and Practice, 6(10), 2015. Recuperado de https:// bit.ly/397rH3r

UNESCO (2017). TIC, Educación y Desarrollo Social en América Latina y el Caribe. Organización de las Naciones Unidas para la Educación, la Ciencia y la Cultura, Recuperado de https://bit.ly/3nnD01A

Pere, M. (2003). Los Videos Educativos, Tipología, Funciones, Orientaciones para su uso. Universidad Autónoma de Barcelona. España. Recuperado de http://peremarques. pangea.org/videoori.htm

Pinto, A., Díaz, J. y Alfaro, C. (2016). Modelo Espiral de Competencias Docentes TICTACTEP aplicado al Desarrollo de Competencias Digitales. Revista Educativa Hekademos, 19, Año IX, 39-48. Recuperado de https://bit.ly/35jxS3h

Sabino, F. (2002). El Proceso de Investigación. Caracas: Panapo.

Samudra, P., Flynn, R. y Wong, K. (2019). Coviewing Educational Media: Does Coviewing Help Low-Income Preschoolers Learn Auditory and Audiovisual Vocabulary Associations? Sage Journals, 2, 1-12. https://doi.org/10.1177\%2F2332858419853238

Semenderiadis, T. y Martidou, R. (2009). Using audiovisual media in nursery school, within the framework of the interdisciplinary approach. Synergies Sud-Esteuropéen, 2, 65-76. Recuperado de https://bit.ly/2MBOz3r

Schneuwly, B. y Bronckart., J. (2012). Vigostky hoy. Editorial Popular Superiores, Barcelona: Crítica.

Torres, P. y Cobo, J. (2017). Tecnología educativa y su papel en el logro de los fines de la educación. Educere, 21(68), 31-40. Recuperado de https://bit.ly/3nwPmzK

Túa, M. (2009). Guía de Estrategias Mediadoras para el Abordaje del Componente Características, Cuidado y Preservación del Ambiente Dirigido a los Docentes de Educación Inicial de la Parroquia el Cují, Municipio Iribarren. Trabajo de Grado para optar al Título de Magister en Educación Mención Educación Inicial. Trabajo de Grado no publicado UPEL- IPB. Estado Lara. Venezuela. 
Yazar, T. y Arifoglu, G. (2012). A research of audio visual educational aids on the creativity levels of 4-14 year old children as a process in primary education. Procedia-Social and Behavioral Sciences, 51, 301-306. https://doi.org/10.1016/j.sbspro.2012.08.163

Zevallos, B. (2018). Aplicación de las TIC en niños de Educación Inicial. Trabajo de Grado, Universidad Nacional de Educación, Perú. Recuperado de https://bit.ly/39aTq3q 